University of Nebraska - Lincoln

DigitalCommons@University of Nebraska - Lincoln

\title{
$5-2011$
}

\section{The Impact of Water Price Uncertainty on the Adoption of Precision Irrigation Systems}

\author{
Karina Schoengold \\ University of Nebraska, Lincoln, kschoengold2@unl.edu \\ David L. Sunding \\ University of California, Berkeley
}

Follow this and additional works at: https://digitalcommons.unl.edu/ageconfacpub

Part of the Agricultural and Resource Economics Commons

Schoengold, Karina and Sunding, David L., "The Impact of Water Price Uncertainty on the Adoption of Precision Irrigation Systems" (2011). Faculty Publications: Agricultural Economics. 107.

https://digitalcommons.unl.edu/ageconfacpub/107

This Article is brought to you for free and open access by the Agricultural Economics Department at DigitalCommons@University of Nebraska - Lincoln. It has been accepted for inclusion in Faculty Publications: Agricultural Economics by an authorized administrator of DigitalCommons@University of Nebraska - Lincoln. 


\title{
The Impact of Water Price Uncertainty on the Adoption of Precision Irrigation Systems
}

\begin{abstract}
The paper examines whether a firm is more or less likely to adopt conservation technology when input prices are stochastic. The results are critical to determining whether programs and contracts that reduce input price uncertainty may deter the adoption of conservation practices. An economic model of the technology adoption decision shows that the net effect of input price risk is ambiguous and depends on several factors: the mean price effect, the shutdown effect, and the risk aversion effect. Results are estimated using water price and irrigation technology adoption data. The results show that a stable input price increases the adoption of conservation technology, but the impact depends on crop choice and land quality characteristics.
\end{abstract}

\section{Introduction}

In many regions there is growing pressure for a limited water supply to provide benefits to a variety of users, including irrigators, residential customers, and industrial producers. Precision irrigation technologies such as drip and microsprinkler systems can help in meeting this multiplicity of needs. Improved technology increases the productivity of a finite natural resource. However, such technologies also have high investment costs and understanding the factors that determine adoption behavior has been the focus of a sizeable literature. The positive impact of higher water prices on the adoption of conservation irrigation technology is well established in the literature (Caswell and Zilberman, 1985; Negri and Brooks, 1990; Green et al., 1996; Moreno and Sunding, 2005; Baerenklau and Knapp, 2007). The cost of providing water to irrigators is driven by energy costs, either through the cost of pumping groundwater or of moving surface water through canals. Thus, uncertainty about energy 
prices fundamentally changes the expected cost of irrigation water. This uncertainty has been exacerbated in recent years by energy price trends that have shown increases in both the mean and variance in recent years. ${ }^{1}$ Due to these trends concerns about price risk may be more relevant in the decision to adopt precision technologies than changes in average prices. While the impact of an increase in the mean price on technology choice is clear, an increase in price risk is less obvious.

This paper answers the question of whether input price risk increases or decreases adoption rates in the context of precision irrigation. The paper contributes to the literature on technology adoption under risk in several ways: it clarifies the ambiguous effect of price risk in the technology adoption decision; it uses field level data on actual production and technology decisions to measure the impact of price risk; and it improves on much of the previous empirical estimation by accounting for the correlation between technology and output choices and for systematic differences in the assignment of price structure to producers. We take advantage of a unique set of data that includes two exogenously determined groups where one group pays a fixed input price and the other pays a stochastic price. By design the mean price paid by the two groups is the same. This allows us to empirically measure the net effect of price risk on irrigation technology choice and discuss the implications for input use and policy design.

Other work has examined the substitution between damaging and non-damaging inputs under input price risk in the context of insurance. Horowitz and Lichtenberg (1993) find evidence that producers enrolled in crop insurance use higher levels of chemicals and interpret this to mean that chemicals are risk-increasing inputs. However, follow-up studies by Babcock and Hennessy (1996) and Smith and Goodwin (1996) find that insured producers use fewer chemical inputs. More recent work shows that the debate is still not fully resolved.

\footnotetext{
${ }^{1}$ For example, the mean price per barrel of oil was $25 \%$ higher in the 2005-2009 period than in the 19751979 period. However, the standard deviation of the price was over 300\% higher. Source: U.S. Energy Information Administration
} 
Sheriff (2005) shows that the result depends on whether polluting inputs are risk-reducing or risk-increasing and Mishra, Nimon, and S. El-Osta (2005) find different results depending on the type of polluting input.

A contribution of the current research is that most existing work only considers the effect of input risk at the intensive margin (shifts in input and output quantities) but not at the extensive margin, which allows firms to shut down or expand as a response to risk. One exception is $\mathrm{Wu}$ (1999), who showed that insurance may decrease the use of polluting inputs at the intensive margin but still increase overall use due to extensive margin effects. Our model allows for extensive margin changes via the decision to temporarily suspend operations.

In this paper, we consider the impact of input price uncertainty on conservation technology adoption. One factor that affects adoption is the expected input price, or mean price. A higher expected price for an input encourages investment in technology that uses the input more efficiently. Risk aversion will also affect levels of adoption. Previous results have shown that risk aversion will increase the adoption of a technology if it is risk reducing (Sandmo, 1971; Feder, 1980; Isik and Khanna, 2003; Koundouri, Nauges, and Tzouvelekas, 2006). Other than a few exceptions (Carey and Zilberman, 2002; Isik and Khanna, 2003; Koundouri, Nauges, and Tzouvelekas, 2006) much of this work measures the impact of uncertainty on the choice of capacity or capital (a continuous variable) and not on the choice between a small number of discrete technologies. In contrast to other articles our paper explicitly considers an individual's ability to temporarily suspend operations (we refer to this as the shutdown effect). ${ }^{2}$ Specifically, we incorporate these three effects (mean price, risk aversion, and shutdown) and distinguish the role of each into an analysis of conservation

\footnotetext{
${ }^{2} \mathrm{~A}$ couple of papers on electricity generation have discussed the importance of considering shutdown effects but have not included them in the economic model (Reedman, Graham, and Coombes, 2006; Wickart and Madlener, 2007). One paper that included the possibility of shutting down did so using numerical simulation (Näsäkkälä and Fleten, 2005). To our knowledge, none has included an economic model adequately accounting for the possibility of shutdown with an empirical estimation using actual adoption decisions.
} 
technology adoption under input price risk.

The paper is organized as follows: Section 2 develops the economic model of technology adoption. Two models are compared, where input prices in the second are a mean-preserving spread of input prices in the first. We find that the impact of fixed input prices on technology adoption depends on several factors: the probability that the firm chooses to operate under high input prices, the cost savings achieved from the conservation technology, and the level of risk aversion. We are able to determine some definitive results about operating decisions. We find that shutdown rates are greater with stochastic input prices, and we also find that shutdown rates are higher under conventional technology than under conservation technology. Section 3 provides a description of the data that we use to test the model and the econometric methods. The data comes from two groups of irrigators where one group pays a fixed price per unit for inputs while the other is subject to fluctuations based on energy markets. Due to differences in the characteristics of each group we need to correct for differences in the sample. We use a pre-processing technique that allows us to use standard parametric estimation while still correcting for sample differences (Ho et al., 2007a). Section 4 concludes the paper with a discussion of the implications of the results.

\section{Economic Model}

The general framework is based on a timeline where a firm must first make a decision about investing in a new conservation technology. When this decision is made the firm knows the distribution of future input prices but not the realization of those prices. After the decision is made about whether to adopt the technology the price uncertainty is resolved and the firm decides whether or not to operate and the level of inputs to use in production. There are many papers that examine investment under uncertainty using a dynamic framework such as the models developed by Dixit and Pindyck (1994). Our model is a simplified version of 
a dynamic decision making process which is presented in a static framework. We are able to make this simplification without losing any useful insight because we assume that while future profits are uncertain, there is no new information that will be learned in future periods and that the realized prices in each future period are independent.

Let $y=h(e)$ be the production function, where we make the standard assumptions that $h^{\prime}(e)>0$ and $h^{\prime \prime}(e)<0$. Let $e=\alpha x$ denote the effective input, where $\alpha$ indicates the input use efficiency (defined between 0 and 1 ) and $x$ indicates applied inputs. With our empirical example of irrigated agricultural production, $x$ is the level of applied water in agricultural production, $e$ is the amount of water actually used by the crop, and $y$ is the yield. We consider two technologies: conservation $(i=1)$ and conventional $(i=0)$, with $\alpha_{1}>\alpha_{0}$. The annualized cost of technology $i$ is $\kappa_{i}$, with $\kappa_{1}>\kappa_{0}$ and this cost must be paid each year regardless of production activities. Therefore, while the sunk cost of investment does not affect the marginal conditions for input use, it does affect the initial decision to adopt a conservation technology. The price of input $x$ is denoted by $w$. In the analysis, we compare the incentives to adopt a conservation technology when $w$ is known with certainty and when $w$ is stochastic. We recognize that there are many other sources of uncertainty to a producer such as output price uncertainty or production uncertainty. However, those factors will affect both groups and can be ignored for the current analysis. The model we develop assumes that long run decisions are made based on a comparison of the optimal short run decisions for each technology. This model of irrigation technology choice is based on the work of Caswell and Zilberman (1986) and has continued to be used in the literature (Green et al., 1996; Isik and Khanna, 2003; Moreno and Sunding, 2005).

\subsection{Input Price Certainty}

We first consider the decision to adopt conservation technology when input prices are known with certainty. We compare the annual profits under each technology to determine if a 
producer will adopt the conservation technology. While the decision to invest in conservation technology is a long run decision and based on a dynamic model when there is no uncertainty a static model will provide the same results with less complexity. Under each technology, the producer chooses the level of inputs based on the following:

$$
\max _{x_{i}} \Pi_{i}=h\left(\alpha_{i} x_{i}\right)-w x_{i}-\kappa_{i}
$$

When there is no uncertainty the producer chooses $x_{i}^{*}(w)$ according to the following:

$$
h^{\prime}\left(\alpha_{i} x_{i}^{*}(w)\right)=\frac{w}{\alpha_{i}}=p_{i}
$$

The left side of equation 1 is the marginal productivity of the input, while the right side is the price per unit of effective input. The conservation technology has a higher level of input-use efficiency $\left(\alpha_{1}>\alpha_{0}\right)$, and therefore the effective price of the input is lower, as fewer inputs are required to achieve the same output level. Figure 1 shows one example of the total and marginal production values as a function of applied water. In Figure 1 the positively sloped curves denote the total production value $(h(\alpha x))$ under the old and new technology (0 and 1 respectively) and the negatively sloped lines denote the marginal value $\left(\alpha h^{\prime}(\alpha x)\right)$. Figure 1 shows a case where the old technology uses a higher level of inputs for the same total production value. However, the relative level of input use and total production value will vary depending on the technology and the input price.

$<<$ Insert Figure $1>>$

When input prices are certain we denote the input price as $w_{c}$ and the change in annual profits from the adoption of conservation technology is the following:

$$
\Delta \Pi=\left\{\left[h\left(\alpha_{1} x_{1}^{*}\left(w_{c}\right)\right)-w_{c} x_{1}^{*}\left(w_{c}\right)\right]-\left[h\left(\alpha_{0} x_{0}^{*}\left(w_{c}\right)\right)-w_{c} x_{0}^{*}\left(w_{c}\right)\right]\right\}-\left\{\kappa_{1}-\kappa_{0}\right\}
$$


Equation 2 compares the net benefit of reducing input use, where the net benefit is measured as the change in net revenue, with the annualized capital costs of the conservation technology. In cases where the output and input-saving effects are greater than the increased capital costs, the conservation technology is adopted. When conservation simply increases input use efficiency, Equation 2 is reduced to comparing the input cost savings with increased capital costs.

\subsection{Input Price Uncertainty}

In this section we consider the decision to adopt conservation technology when future input prices are uncertain. For the analysis to hold, at least some portion of the capital cost of adopting conservation technology must be irreversible. We assume that the input price has cumulative distribution $F(w)$ and probability distribution $f(w)$ which is distributed between $w_{L}$ and $w_{H}$ with mean $w_{c}$ and standard deviation $\sigma_{w}$. This assumption ensures that the price distribution is a mean-preserving spread of the fixed price in Section 2.1.

\subsubsection{Short-run decisions}

We consider the choice of technology as a long run decision. Therefore, in the short run a producer has two decisions: whether to temporarily suspend operations and the level of variable inputs to use. The decisions are made by first solving for the optimal input level given the realized input price, and then determining if it is profitable to operate. For technology $i$, we define $x_{i}^{*}(w)$ according to the condition in Equation 1, which sets the marginal productivity of the input equal to its effective price. After observing the realization of stochastic input prices, producers may choose to suspend operations. We denote the shutdown input price for each technology as $\tilde{w}_{i}\left(h(),. \alpha_{i}\right)$. This price is defined by the zero profit condition:

$$
h\left(\alpha_{i} x_{i}^{*}\left(\tilde{w}_{i}\right)\right)-\tilde{w}_{i} x_{i}^{*}\left(\tilde{w}_{i}\right)=0
$$


The condition in Equation 3 ensures that all operating producers are able to cover the variable costs of production. If $\tilde{w}_{i}>w_{H}$ a producer will not shut down. While this is outcome is possible it is not interesting for the economic model so we consider the case where $\tilde{w}_{i}<w_{H}$. Totally differentiating Equation 3 with respect to $\alpha_{i}$ and $\tilde{w}_{i}$ shows that producers operate over a greater range of input prices with higher input use efficiency and that the shutdown price is higher under conservation technology.

\subsubsection{Technology Adoption under Uncertain Input Prices}

In the long run, producers must decide whether to use the conventional technology or to invest in conservation technology. We assume that a risk averse firm maximizes the expected utility of future profit. We denote the mean and standard deviation of profit as $\mu$ and $\sigma$ respectively. We assume that utility is a function of the first two moments of the profit function and denote it as $U(\mu, \sigma)$ with $U_{\mu}>0$ and $U_{\sigma}<0$. This framework was developed by Meyer (1987) and has been used by many authors (Isik and Khanna, 2003; Munshi, 2004; Gaynor and Gertler, 1995).

Operating decisions are made after the input price is realized so we denote the realized profit for value of $w$ as $\Pi^{*}(w)$. For each technology the realized profit is $\Pi^{*}(w)=h\left(\alpha_{i} x_{i}^{*}(w)\right)-$ $w x_{i}^{*}(w)-\kappa_{i}$ if $w \leq \tilde{w}_{i}$ and $\Pi^{*}(w)=-\kappa_{i}$ if $w>\tilde{w}_{i}$.

The per-period expected profit under each type of technology is the following:

$$
\begin{aligned}
& \mu_{0}=\int_{w_{L}}^{\tilde{w}_{0}}\left(h\left(\alpha_{0} x_{0}^{*}(w)\right)-w x_{0}^{*}(w)\right) d f(w)-\kappa_{0} \\
& \mu_{1}=\int_{w_{L}}^{\tilde{w}_{1}}\left(h\left(\alpha_{1} x_{1}^{*}(w)\right)-w x_{1}^{*}(w)\right) d f(w)-\kappa_{1}
\end{aligned}
$$

To determine conservation technology adoption, we compare Equations 4 and 5 .

Risk aversion did not enter the model in the previous sections since all of the decisions are made under certainty. However, technology adoption decisions are made under uncertainty 
about future prices and profits. It is assumed that the conservation technology $(i=1)$ has a higher level of input-use efficiency, denoted by $\alpha_{1}>\alpha_{0}$. Therefore, the variance of the price of effective water (i.e., the water that is actually used by the firm) is lower with the conservation technology. When $w$ is distributed with variance $\sigma^{2}$ the variance of the effective price is $\operatorname{Var}\left(p_{i}\right)=\left(\frac{1}{\alpha_{i}}\right)^{2} \sigma^{2}$ and $\operatorname{Var}\left(p_{1}\right)<\operatorname{Var}\left(p_{0}\right)$. A producer will adopt the conservation technology when the expected utility is higher than with the conventional technology. Taking a first order approximation of the difference in utility from the two technologies shows the following:

$$
\begin{aligned}
U\left(\mu_{1}, \sigma_{1}\right)-U\left(\mu_{0}, \sigma_{0}\right) & \approx \mu_{1}-\mu_{0}+\frac{U_{\sigma}}{U_{\mu}}\left(\sigma_{1}-\sigma_{0}\right) \\
= & \int_{w_{L}}^{\tilde{w}_{0}}\left(\left(h\left(\alpha_{1} x_{1}^{*}(w)\right)-w x_{1}^{*}(w)\right)-\left(h\left(\alpha_{0} x_{0}^{*}(w)\right)-w x_{0}^{*}(w)\right)\right) d f(w) \\
+ & \int_{\tilde{w}_{0}}^{\tilde{w}_{1}}\left(h\left(\alpha_{1} x_{1}^{*}(w)\right)-w x_{1}^{*}(w)\right) d f(w)-\left(\kappa_{1}-\kappa_{0}\right)+\frac{U_{\sigma}}{U_{\mu}}\left(\sigma_{1}-\sigma_{0}\right)
\end{aligned}
$$

To determine how a shift to fixed input prices changes the incentive for technology adoption we compare Equation 2 and 6 and examine the expression for $\Delta \Pi-\left(U\left(\mu_{1}, \sigma_{1}\right)-U\left(\mu_{0}, \sigma_{0}\right)\right.$. If this expression is positive, the incentive to adopt is higher with fixed input prices. Substituting $\Delta \tilde{\Pi}\left(w_{c}\right)$ for $\Delta \Pi+\left(\kappa_{1}-\kappa_{0}\right)$ and $\Delta \widehat{\Pi}(w)$ for $\left(h\left(\alpha_{1} x_{1}^{*}(w)\right)-w x_{1}^{*}(w)\right)-\left(h\left(\alpha_{0} x_{0}^{*}(w)\right)-\right.$ $\left.w x_{0}^{*}(w)\right)$ we have the following:

$$
\begin{aligned}
\Delta \Pi & -\left(U\left(\mu_{1}, \sigma_{1}\right)-U\left(\mu_{0}, \sigma_{0}\right)\right)=\underbrace{\left(1-F\left(\tilde{w}_{0}\right)\right) \Delta \tilde{\Pi}\left(w_{c}\right)}_{A} \\
& +\underbrace{\left(F\left(\tilde{w}_{0}\right) \Delta \tilde{\Pi}\left(w_{c}\right)-\int_{w_{L}}^{\tilde{w}_{0}} \Delta \widehat{\Pi}(w) d f w\right)-\left(\int_{\tilde{w}_{0}}^{\tilde{w}_{1}}\left(h\left(\alpha_{1} x_{1}^{*}(w)\right)-w x_{1}^{*}(w)\right) d f(w)\right)}_{B} \\
& -\underbrace{\frac{U_{\sigma}}{U_{\mu}}\left(\sigma_{1}-\sigma_{0}\right)}_{C}
\end{aligned}
$$


Part $A$ of Equation 7 is the shutdown effect. This is the range of input prices where a producer needs to shut down with stochastic prices. This is unambiguously positive. The impact of the shutdown effect is to increase adoption rates under fixed input prices. Part $B$ of Equation 7 is the mean price effect and measures the net benefit for producers of being able to take advantage of low input prices with a stochastic input price. The sign of this is ambiguous: the combined effect of the first two terms is positive since the expected value of $w$ over the range $\left(w_{L}, \tilde{w}_{0}\right)$ is less than $w_{c}$, and the third term is negative since the conservation technology increases the range of profitability under stochastic input prices. Part $C$ of Equation 7 is the risk aversion effect. This measures the additional incentive that producers have to adopt a risk-reducing conservation technology under stochastic input prices. The risk aversion effect is unambiguously negative for risk-averse producers. The first component of part $C$ is the ratio of the marginal disutility of profit risk to the marginal utility of wealth. This is a standard risk preference measure, is negative for a risk-averse producer, and the absolute value increases with the level of risk aversion. Since $\operatorname{Var}\left(p_{1}\right)<\operatorname{Var}\left(p_{0}\right)$ we know that the second part of $C$ is also negative. Under risk neutrality part $C$ is zero and the difference in adoption rate is due to the shutdown and mean price effects..

The results of the analytical model show that shutdown rates are greater with stochastic input prices and higher with conventional technology than with conservation technology. However, the net effect of stochastic input prices is ambiguous in determining conservation technology adoption behavior.

\section{Empirical Analysis}

In this section we apply the results of the analytical model to a unique data source that includes information on technology choice, input price uncertainty, and shutdown rates. This allows us to empirically test the economic model and to determine which factors are 
dominant in predicting actual adoption and shutdown behavior.

\subsection{Data}

To answer this question, we combine data from several sources. The data on land use comes from Arvin Edison Water and Storage District (AEWSD), a utility serving approximately 275 farming operations that are located 90 miles north of Los Angeles, California. AEWSD collects technology and output choice data at the field level.

The data has field level information for 4,764 fields on crop choice (an average of 1,191 per year), irrigation technology, and water service area. The data covers the 1999-2002 period. Information on the price of groundwater was estimated in 1993 by AEWSD based on the depth to groundwater (Green et al., 1996) or based on the marginal price for surface water. We adjust the estimated prices for groundwater users to the study years using the Consumer Price Index (CPI) and update the marginal price for surface water based on AEWSD water rates. For groundwater users, this price captures differences in the depth to groundwater across the district. The price will also vary based on energy prices and we use annual fixed effects to capture differences in the price of energy over time. Finally, we use landowner information from the Kern County Tax Assessor office. We are able to match the landowner with the field level information using the Assessor Parcel Number, or APN. While we can match the landowner with the field information we are unable to track a single field over time due to the structure of the data. ${ }^{3}$ The field level data includes one observation for each unique crop-technology pair, implying that a single APN appears in the data multiple times in a single year.

\footnotetext{
${ }^{3}$ Since we cannot track a single field over time we are not able to use standard panel data methods for the analysis. However, we do several checks to ensure that this issue does not change our results. First, we include year indicator variables for all of our analysis. We also run the full analysis for a single year of data and find that the results are not significantly different than when we include the pooled data.
} 


\subsubsection{Environmental variables}

Previous research has shown that field level variation on environmental quality characteristics such as slope, soil quality, and average climate are important explanatory variables in determining production choices on crop and irrigation technology (Caswell and Zilberman, 1985; Lichtenberg, 1989; Ogg and Gollehon, 1989; Green et al., 1996; Moreno and Sunding, 2005). For example, previous papers have found that owners of low quality land are more likely to adopt conservation irrigation technology, as the relative gains from adoption are greater than with high quality land. The environmental variables used are chosen to reflect soil and topography characteristics relevant to farming and irrigation. These variables (slope, elevation, soil permeability, number of frost-free days per year, average precipitation and average temperature) are long run averages and do not change over time, but do vary between sections. These variables were collected by the Kern County Natural Resource Conservation Service, and are described in more detail in Green et al. 1996. These data address the cross-sectional variation among microclimates within AEWSD.

\subsubsection{Production variables}

The data set contains an observation on crop and irrigation technology for each field under production and is recorded for the spring and fall planting seasons. The region has a mix of crops including perennial crops such as grapes and oranges, annual crops such as carrots and onions, and field crops such as hay and alfalfa. There is also a lot of variation in the type of irrigation system used with drip, sprinkler, gravity, and microsprinkler all used extensively. Table 1 shows the distribution by crop and technology type. Both crop and irrigation technology types are well represented, with annual crops and conservation irrigation on 38.7 and 79.0 percent of the fields, respectively.

$$
\begin{aligned}
& <<\text { Insert Table } 1>> \\
& <<\text { Insert Table } 2>>
\end{aligned}
$$


Table 2 shows that both groundwater and surface water areas are well represented in the data, with 55.6 and 44.4 percent of the fields, respectively. We define conservation technology as drip or sprinkler irrigation. We include both perennial and annual crops in the empirical analysis although we expect that the impact of input price risk will differ between the two categories. Thus, we will need to incorporate this difference in our empirical methodology. In particular, the shutdown effect that we discussed earlier is not a viable option with perennial crops. ${ }^{4}$ These crops represent long term investments in a similar manner as conservation irrigation. With annual crops, planting decisions get made on a yearly basis, allowing a producer to respond quickly to changing conditions and prices. Shutting down is a valid option with annual crops through fallowing land, which we use as our indicator of the shutdown decision discussed in the analytical model. In addition, evidence from previous research shows that the decisions to adopt conservation irrigation and permanent crops are highly correlated and we need to correct for this potential bias (Lichtenberg, 1989; Moreno and Sunding, 2005; Schoengold, Sunding, and Moreno, 2006).

\subsubsection{Land Ownership Information}

We use information on land ownership to provide a measure of risk attitude. There are a variety of methods used in the literature to estimate risk preferences. Recent work by Pope, LaFrance, and Just (2011) suggests using techniques based on portfolio theory to measure risk attitudes by using investment decisions. That method requires information on wealth, which we do not have available for the AEWSD region. Other methods have been developed by Antle (1987) to use input and output data to measure risk attitudes, and these methods have been applied to decisions made about water availability uncertainty (Groom et al., 2008). These methods are useful for disentangling risk attitudes based on production data but require complete input and output data for at least one production activity. In

\footnotetext{
${ }^{4}$ While fallowing perennial crops is not an option producers do have some flexibility in the amount of water applied, and applying less water for reduced yields is an option when the effective water price is high.
} 
the current paper we have land use data (crop and irrigation technology) but we lack any data on yields or other production inputs. However, previous literature has found that farm size is a significant predictor of risk attitudes, with farm size negatively correlated with risk aversion (Saha, Love, and Schwart, 1994; Koundouri et al., 2009). When separating relative and absolute risk aversion, Saha, Shumway, and Talpaz (1994) found that small farms have higher absolute risk aversion and lower relative risk aversion than large farms.

Using tax information from the Kern County Tax Assessor we are able to create a landowner ID for each field in our sample and a measure of total land holdings for each landowner. Since we are interested in how a landowner chooses to manage his or her agricultural land we use the total area in agricultural land (Farmsize), which is measured in thousands of acres. This measure will include land that is left fallow. The average landowner in AEWSD has 309.4 acres although this is highly skewed. A few landowners have more than 2000 acres in agricultural land while the majority have less than 200 acres. We use this measure as a proxy for risk attitude.

\subsection{Water Service Area as an Indicator of Price Risk}

Unlike many irrigation districts, users in AEWSD are divided into surface and groundwater users, with each being a distinct group (denoted by $W S A)$. Surface water users $(W S A=1)$ are not allowed to dig wells or pump groundwater, so we know that surface water is their marginal source for irrigation, while groundwater is the only source of irrigation for the second group. This distinction is exogenous to an individual land owner and is fixed over time for a particular field. The pricing structure that AEWSD has developed is designed to keep the mean water price the same for both groundwater and surface water users (Green et al., 1996). However, surface water users pay a fee and have water delivered directly to their fields, while groundwater users pay a reduced fee, but have to pay the full costs of pumping. In both cases the fixed component of the total charge is low relative to the variable cost. 
For surface water users, the fixed fee is $\$ 94$ per acre. While this is higher than the variable fee of $\$ 65$ or $\$ 51$ per acre-foot, the district assumes an average application rate of 2.75 acre-feet per acre. Therefore, on average a producer using surface water pays $\$ 140$ to $\$ 179$ per acre for the variable fee and the fixed fee is 34 to 40 percent of total water costs. Groundwater users pay a smaller fixed fee of $\$ 23$ per acre. The largest variable cost to groundwater users is diesel fuel, which has a price that varies based on market conditions. Based on the range of depth to groundwater in the area and average water application rates, the fixed fee is between 8.5 and 17 percent of total water cost for groundwater users.

To incorporate differences in the average water price across the district we include a price for water. The price for water was estimated in 1993 by AEWSD based on the depth to groundwater (for groundwater users) and the marginal price of water delivery (for surface water users). The Water price variable captures differences in the average price between groundwater users and allows us to identify the mean price effect from Equation 7. The price that groundwater users actually pay will vary around this average based on energy prices while the price for surface water users is fixed. Since we cannot track a single field over time we cannot empirically measure the shutdown effect from Equation 7 . However we have evidence that groundwater users shut down operations more frequently than surface water users. For fields that grow annual crops leaving the field fallow in the fall (the second growing season) is an option. Overall approximately 66 percent of the fields with annual crops in the spring season are left fallow in the fall season while the other 34 percent of the fields are replanted. Based on the economic model, we expect that fallowing will occur more frequently with stochastic input prices. In the groundwater (surface water) area, 71 (63) percent of the fields in annual crops are left fallow in the fall season. ${ }^{5}$

The underlying question that we want to answer is if producers facing a stochastic input price are more likely to adopt conservation technology than those facing a fixed input price.

\footnotetext{
${ }^{5}$ Using a means test we find this difference is statistically significant at the $99 \%$ level.
} 
In the data, the variable that represents the input price structure is the water service area $(W S A)$. The price of pumping groundwater is based on the depth to groundwater and the cost of fuel. The depth to groundwater in AEWSD ranges between 200 and 500 feet, although the depth is fairly constant for a single field (GWB, 2006). The cost of diesel fuel during the sample period ranges between $\$ 1.10$ and $\$ 1.70$ per gallon, with the price during most of the period under $\$ 1.50 .{ }^{6}$ Using assumptions about technology for a standard well, Figure 2 shows how the marginal cost of pumping groundwater varies during the sample period by depth to groundwater.

$<<$ Insert Figure $2>>$

Figure 2 also shows the variable fee that surface water irrigators pay per acre-foot of water. In contrast to the variability in groundwater prices, rates for surface water are stable during the study period. The variable fee was reduced in 1998 from about $\$ 65$ to about \$51. The reason for the price change is that AEWSD found that they were over-collecting revenue, and water districts in California operate on a revenue-neutral basis. A comparison of the prices paid by the two groups of irrigators shows that the range of variable prices for irrigation water has a large area of overlap between the two users.

\subsection{Econometric Model}

The primary question that we want to answer is if stochastic input prices increase or decrease conservation technology adoption. The difficulty in measuring this is that we only observe adoption choices for a particular field under a single rate structure. To estimate the impact of the Water Service Area (WSA) on conservation technology adoption there are several possible estimation strategies.

One method to do this is with a probit analysis of the irrigation technology. There are two issues that are of concern, both of which might result in biased parameter estimates if

\footnotetext{
${ }^{6}$ Historical diesel prices were obtained from the U.S. Energy Information Administration.
} 
we use a single probit estimation. First, we are concerned about the differences between the two samples. For this method to be consistent, it requires that the two water service areas are sufficiently similar in the explanatory variables. If there are systematic differences in the explanatory variables between the two WSAs, a single estimation which uses the entire sample may be biased. This is potentially a problem because the two service areas are not distributed evenly. Due to infrastructure development, fields that use surface water are likely to be adjacent to other fields that also use surface water. The non-random geographic distribution of the treatment means that land quality characteristics such as slope and soil permeability are not distributed evenly between the two service areas. Second, previous literature has shown a significant correlation between crop choice and irrigation technology (Lichtenberg, 1989; Moreno and Sunding, 2005). Not accounting for this correlation may lead to biased estimates of the effect of the water service area.

Some of the land quality characteristics vary across the irrigation district, and therefore could be correlated with the water service area as well as the technology choice. Table 3 shows the differences in the means of the explanatory variables for the full sample. The test of mean differences shows the t-statistic for continuous variables and the z-statistic for discrete variables, which measures the statistical significance of the differences between the two samples. A comparison of the two samples shows that this concern is valid. Almost all of the township variables are significantly different, which confirms that surface and groundwater users are not randomly distributed over the district. There are also large differences in many of the land quality variables. Fields in the groundwater service area have, on average, lower slope (Slope), higher soil permeability (Permeability), and are located at a lower elevation than fields in the surface water area. The township variables, which are geographical locations, show that the proportion of land in each township is statistically different between the two water service areas. While the difference between the variables is consistently statistically significant, the magnitude of the differences does vary. 
For example, the mean number of frost-free days (Frost-free days) and average temperature (Temperature) differs by less than one percent while the average values for soil permeability and slope differ by more than 30 percent.

$<<$ Insert Table $3>>$

An estimation strategy that can reduce the bias associated with differences in the two groups is to use propensity score matching, where each observation from the control group is matched with an observation from the treatment group. The propensity score is the estimated probability of being treated (in this case treatment refers to being part of the surface water area) conditional on observable variables.

While using the propensity score is better than neglecting the differences in the two samples, it does require matching based on observable characteristics and limits the range of econometric estimation techniques that we can use. An alternative estimation strategy that has been proposed by Ho et al. (2007a) is to preprocess the data before estimating treatment effects. By preprocessing the data, we look for the common support of the two samples over the observable characteristics and drop those observations that fall outside of the common support. While this reduces the number of total observations, the benefit is that econometric analysis of the matched data set will not have the bias of using the entire sample. We preprocess the data using the $\mathrm{R}$ software MatchIt package developed by Ho et al. (2007b). We match the observations using slope, soil permeability, elevation, and we require an exact match for the township variable.

$<<$ Insert Figure $3>><<$ Insert Figure $4>>$

Figures 3 and 4 provides a comparison of the estimated propensity score for the treatment and control samples before and after matching. Before matching, the control group has a much higher proportion of the distribution with propensity scores below 0.30 and that proportion is reduced in the matched control sample. This corresponds to an increased proportion of the control group with propensity scores in the [0.30 0.60] interval after matching. 
The distribution of the propensity score for the treatment group (the surface water area) is much closer to the initial distribution after matching, as fewer observations are dropped from this sample during the matching process. However, this group also shows that the proportion of observations in the [0.30 0.60] range is higher after matching. Figure 4 shows a jitter plot of the same information. This shows that the observations dropped from the control group are mostly those with propensity scores less than 0.3 while the dropped treatment observations span a wider range.

\subsubsection{Bivariate Probit Results of the Decision to Adopt Conservation Technol- ogy}

Using the preprocessed data allows us to estimate the impact of the water service area variable on the adoption of conservation irrigation with greater confidence that the result is due to the actual difference in the water source (i.e., the input price variation) instead of being due to other observable differences in the two samples.

The second issue we need to resolve with is that irrigation technology is not independent of crop choice. In particular, the distinction between perennial crops and annual crops is an important one in evaluating adoption choices. Perennial crops such as grapes and oranges require a large initial investment. In addition, fallowing land is a limited option with perennial crops. Adopting efficient irrigation with annual crops requires an investment but the option to fallow land for a season is an option. As we showed in the economic model, the shutdown effect may be a driver of higher technology adoption rates under fixed input prices.

To estimate land use choices we use a bivariate probit which allows us to jointly estimate crop and irrigation technology. The bivariate probit model uses maximum likelihood to

estimate a bivariate normal distribution, where $\Phi\left(x_{1}, x_{2}, \rho\right)=\int_{-\infty}^{x_{1}} \int_{-\infty}^{x_{2}} \phi\left(z_{1}, z_{2}, \rho\right) d z_{1} d z_{2}$ where $\Phi($.$) is the cumulative distribution function and \phi($.$) is the cumulative density function.$ 
By using this method we can estimate the overall impact of input price risk (measured by the water service area) and how this impact differs by crop type. We first verify the accuracy of the estimation by comparing the percentage of fields that are correctly predicted. We consider a field to be correctly predicted if the probability associated with the actual technology-crop value is over 0.5 . We find strong evidence that the model does an accurate job of predicting outcomes, with 65.3 and 77.4 percent of the observations correctly predicted for the larger groups (those with efficient irrigation) and 80.7 and 100 percent correctly predicted for the smaller groups.

$<<$ Insert Table $4>><<$ Insert Table $5>>$

The coefficients and marginal effects of the bivariate probit estimation are in Table 5 . Columns (1) and (2) show the estimated coefficients for the full sample and columns (5) and (6) show the estimated coefficients for the matched sample. The coefficients are estimated using maximum likelihood. The estimated correlation between the two equations is significant in both estimations, which shows the importance of estimating the two equations jointly instead of separately. Many of the interaction terms are significant, providing evidence that the impact of moving to a fixed input price or increasing the price of water is not the same for all fields and firms. For example, the negative coefficients on the interaction terms with Water price and land quality characteristics such as slope and permeability in the irrigation technology equation show that while a higher water price increases the use of efficient irrigation, this effect is reduced for land with a high slope or soil permeability. This is likely due to the fact that land with a high slope and soil permeability gain more from precision irrigation, and thus are likely to adopt even at low water prices. Overall, the coefficients on the land quality characteristics are of less significance in the crop choice equation than in the irrigation technology equation. This may be due to the fact that the relative importance of land quality characteristics are relatively more important in determining irrigation technology since general market conditions are a major determinant of crop choice. 
To fully understand the impact of these coefficients we need to use the marginal effects, incorporating both the direct coefficient and any interaction terms. Columns (3)-(4) and (7)-(8) show the estimated marginal effects for each variable, which are estimated conditional on the values for each observation. Specifically, the estimated marginal effects show $(\partial E[$ effirrig $=1 \mid x]) / \partial x$. The marginal effects show some interesting patterns and are generally consistent with our expectations. Most of the results are similar between the full and matched sample although there are some important differences that are apparent in the marginal effects. One difference is that the marginal effects of some of the land quality characteristics are lower in the matched sample than in the full sample. For example the marginal effect of slope decreases from 13.6 to 9.8 percent. The coefficient on permeability also decreases by 7 percent. These results indicate that the coefficients in the full sample estimation are affected by the fact that the two samples are not sufficiently similar, leading to some bias in the estimated coefficients.

The economic model predicts that the risk aversion effect will lead to higher adoption rates for individuals that are more risk-averse, particularly under stochastic input prices. One interesting result is that the marginal effect of firmsize, which is a proxy for a lower degree of risk aversion, is negative and significant in both the irrigation and crop estimation. The magnitude of the effect is higher with the matched sample, providing additional evidence that samples may differ before pre-processing. Previous research has shown that large operations tend to be less risk averse than small operations (Saha, Love, and Schwart, 1994; Saha, Shumway, and Talpaz, 1994; Koundouri et al., 2009). This result indicates that both efficient irrigation and perennial crops are used as risk reducing investments by small operations. This result is consistent with the fact that perennial crops are a type of investment that reduces future profit variability.

First, the effect of risk aversion, which we proxy using firm size, is as we expect. The marginal effect of increasing firm size by 1000 acres is a 1.9 and 3.8 percent reduction in 
the probabilities of using efficient irrigation and perennial crops. While an increase of 1000 acres is large relative to the mean in the sample, increased consolidation in the agricultural industry is likely to lead to the average firm size increasing.

The central question that we want to answer in the paper is how moving from stochastic to fixed input prices affects the adoption of conservation technology. When we use the full sample without accounting for differences in the characteristics of the surface and groundwater groups we that surface water users are 12.5 percent more likely to use precision irrigation. However, once we account for the sample differences we find that surface water users are 9.3 percent more likely to invest in precision irrigation, a difference of approximately 25 percent. In both cases, we find clear evidence that stable input prices increase the rate of efficient technology adoption. This provides evidence that shutdown effect and the positive portion of the mean price effect more than compensate for the risk aversion effect and the negative portion of the mean price effect. This is consistent with the hypothesis that a fixed water price that assures a reliable supply at a predetermined price leads to greater levels of adoption, presumably since surface water users are more confident of earning a profit as they do not face input price risk. Not surprisingly, areas with a higher average price (Water price) are more likely to adopt precision irrigation.

We also find that the water service area is a significant indicator of the decision to adopt perennial crops, with surface water users 16.5 percent more likely to adopt crops such as grapes or citrus. This makes sense in the economic framework, since the choice of crop does not directly change the input use efficiency and effective price for water. Consistent with this result, we find that Water price has no significant effect in the crop choice equation. Finally, the positive marginal effect of field size on perennial crop adoption and insignificant effect on efficient irrigation adoption shows that there are differences in the economies of scale associated with these two investments. Perennial crops show a higher level of economies of scale while that relationship does not exist with efficient irrigation. Most of the other land 
quality variables show the expected sign, with higher values for slope and soil permeability increasing the probability of adopting conservation irrigation. This is consistent with agronomic realities which show that conservation irrigation can reduce runoff from fields and that this effect is higher with higher soil permeability and slope.

These results, which show that stable input prices may increase the use of conservation technologies are important if policymakers want to increase the use of efficient technology. This paper estimates these effects using data on irrigation technology adoption in agriculture but the same concerns are relevant in understanding how fuel or electricity rates affect the use of energy efficient appliances. In fact, trying to reduce price uncertainty it is a common practice for water, energy, or electricity utilities to offer fixed-rate contracts to customers. For example, Black Hills Energy, a natural gas provider, recently offered customers an option to sign up for an APO, or Annual Price Option which would guarantee a fixed price for a 12-month period. ${ }^{7}$ The results from the current paper suggest that these types of offers may increase a customer's incentive to adopt energy efficient technologies. Further work needs to be done to examine the impact of input price use on decision making across a range of industries.

While the result show strong statistical evidence that fixed input prices increase the adoption of conservation irrigation technology, there are some limitations to the analysis. One limitation is that we cannot track an individual field over time to determine when investment decisions take place, we only observe the status of a field in a particular year. This is a concern in both the analysis we present with multiple years and with the testing that we do with a single year of data. We have incorporated many characteristics of the individual field but we only have limited information about the landowner. We expect that having additional information about each landowner would allow better identification of the

\footnotetext{
${ }^{7}$ This offer was sent to customers in Nebraska, and offered a set price of $\$ 0.61764$ per therm, not including fees and taxes, for the period from November 2010 - October 2011. The program is not designed to save customers money over the period, and the price is set to be revenue neutral based on expected prices.
} 
characteristics that affect risk preferences and technology choice. Finally, we expect that the results of our general economic model may be even more important in an industry where temporarily shutting down operations for a short period (hours or days) is feasible. There is little empirical evidence examining this question and we leave it to future research to do so.

\section{Conclusion}

In this paper, we look at the incentives for a firm or producer to adopt conservation technology, and compare those incentives when input prices are fixed and when they are stochastic. The results are important in determining the effects of policies and programs designed to reduce price uncertainty. For example, firms that can contract with input suppliers face a more certain input price than firms without that ability. Understanding how this impacts a decision to adopt conservation practices is important in determining the potential demand for new conservation technologies, or in understanding observed behavior. We show that there are three effects of a shift to fixed input prices on the adoption of technologies that conserve the input: the shutdown effect, the mean price effect, and the risk aversion effect. The shutdown effect increases adoption rates under fixed prices since shutting down is not necessary. The mean price effect has two components: a lower effective price under stochastic prices and a greater range of operation with conservation technology. The net effect of this is ambiguous. Finally, the risk aversion effect increases the probability of adopting a technology under input price risk.

The empirical analysis uses data on conservation technology adoption in the irrigated agriculture sector. A unique aspect of this data is that the producers are divided into two separate groups, where one group faces a fixed input price while the other has to purchase inputs where the price depends on market conditions. After preprocessing the data, a technique that allows us to measure the impact of the fixed input price consistently, we find that 
there is a positive average treatment effect, and that moving from stochastic to fixed input prices increases the use of conservation technology. This is an encouraging result, given the increased use of fixed price contracts for inputs in both energy and agricultural sectors. This result suggests that policies that are designed to promote the use and adoption of conservation technology may need to incorporate market and contract design in developing new programs. Our results also show the importance of correcting for sample differences in an appropriate way when trying to estimate treatment effects. Not doing so may lead to biased estimates of technology adoption behavior. 


\section{References}

2006. "California Groundwater Bulletin 118."

Antle, J. 1987. "Econometric Estimation of Producers' Risk Attitudes." American Journal of Agricultural Economics 69:509-522.

Babcock, B.A., and D.A. Hennessy. 1996. "Input Demand under Yield and Revenue Insurance." American Journal of Agricultural Economics 78:416-427.

Baerenklau, K.A., and K.C. Knapp. 2007. "Dynamics of Agricultural Technology Adoption: Age structure, reversibility, and uncertainty." American Journal of Agricultural Economics 89:190201.

Carey, J.M., and D. Zilberman. 2002. "A Model of Investment under Uncertainity: Modern Irrigation Technology and Emerging Markets in Water." American Journal of Agricultural Economics 84:171-183.

Caswell, M., and D. Zilberman. 1985. "The Choices of Irrigation Technologies in California." American Journal of Agricultural Economics 67:224-234.

-. 1986. "The Effect of Well Depth and Land Quality on the Choice of Irrigation Technology." American Journal of Agricultural Economics 68:798-811.

Dixit, A.K., and R.S. Pindyck. 1994. Investment under Uncertainty. Princeton University Press.

Feder, G. 1980. "Farm Size, Risk Aversion and the Adoption of New Technology under Uncertainty." Oxford Economic Papers 32:263-83.

Gaynor, M.G., and P. Gertler. 1995. "Moral Hazard and Risk Spreading in Partnerships." The RAND Journal of Economics 26:591-613.

Green, G., D. Sunding, D. Zilberman, and D. Parker. 1996. "Explaining Irrigation Technology Choices: A Microparameter Approach." American Journal of Agricultural Economics 78:1064-1072.

Groom, B., P. Koundouri, C. Nauges, and A. Thomas. 2008. "The story of the moment: risk averse Cypriot farmers respond to drought management." Applied Economics 40:315326.

Ho, D.E., K. Imai, G. King, and E.A. Stuart. 2007a. "Matching as Nonparametric Preprocessing for Reducing Model Dependence in Parametric Causal Inference." Political Analysis 15:199-236.

—. 2007b. "Matchit: Nonparametric Preprocessing for Parametric Causal Inference." Journal of Statistical Software, pp. . 
Horowitz, J.K., and E. Lichtenberg. 1993. "Insurance, Moral Hazard, and Chemical Use in Agriculture." American Journal of Agricultural Economics 75:926-935.

Isik, M., and M. Khanna. 2003. "Stochastic Technology, Risk Preferences, and Adoption of Site-Specific Technologies." American Journal of Agricultural Economics 85:305-317.

Koundouri, P., M. Laukkanen, S. Myyrä, and C. Nauges. 2009. "The effects of EU agricultural policy changes on farmers risk attitudes." European Review of Agricultural Economics $36: 5377$.

Koundouri, P., C. Nauges, and V. Tzouvelekas. 2006. "Technology Adoption under Production Uncertainty: Theory and Application to Irrigation Technology." American Journal of Agricultural Economics 88:657-670.

Lichtenberg, E. 1989. "Land Quality, Irrigation Development and Cropping Patterns in the Northern High Plains." American Journal of Agricultural Economics 71:187-194.

Meyer, J. 1987. "Two-Moment Decision Models and Expected Utility Maximization." American Economic Review 77:421-430.

Mishra, A.K., R.W. Nimon, and H. S. El-Osta. 2005. "Is moral hazard good for the environment? Revenue insurance and chemical input use." Journal of Environmental Management $74: 11-20$.

Moreno, G., and D.L. Sunding. 2005. "Joint Estimation of Technology Adoption and Land Allocation with Implications for the Design of Conservation Policy." American Journal of Agricultural Economics 87:1009-1019.

Munshi, K. 2004. "Social learning in a heterogeneous population: technology diffusion in the Indian Green Revolution." Journal of Development Economics 73:185-213.

Näsäkkälä, E., and S.E. Fleten. 2005. "Flexibility and technology choice in gas fired power plant investments." Review of Financial Economics 14:371393.

Negri, D.H., and D.H. Brooks. 1990. "Determinants of Irrigation Technology Choice." Western Journal of Agricultural Economics 15:213-223.

Ogg, W., Clayton, and N.R. Gollehon. 1989. "Western Irrigation Response to Pumping Costs: A Water Demand Analysis Using Climatic Regions." Water Resource Research 25:767-773.

Pope, R.D., J.T. LaFrance, and R. Just. 2011. "Agricultural arbitrage and risk preferences." Journal of Econometrics 162:35-43.

Reedman, L., P. Graham, and P. Coombes. 2006. "Using a Real-Options Approach to Model Technology Adoption Under Carbon Price Uncertainty: An Application to the Australian Electricity Generation Sector." The Economic Record 82:S64-S73. 
Saha, A., H.A. Love, and R. Schwart. 1994. "Adoption of Emerging Technologies under Output Uncertainty." American Journal of Agricultural Economics 76:836-846.

Saha, A., C.R. Shumway, and H. Talpaz. 1994. "Joint Estimation of Risk Preference Structure and Technology Using Expo-Power Utility." American Journal of Agricultural Economics 76:173-184.

Sandmo, A. 1971. "On the Theory of the Competitive Firm Under Price Uncertainty." American Economic Review 61:65-73.

Schoengold, K., D.L. Sunding, and G. Moreno. 2006. "Price Elasticity Reconsidered: Panel Estimation of an Agricultural Water Demand Function." Water Resources Research 42.

Sheriff, G. 2005. "Efficient Waste? Why Farmers Over-Apply Nutrients and the Implications for Policy Design." Review of Agricultural Economics 27:542-557.

Smith, V.H., and B.K. Goodwin. 1996. "Crop Insurance, Moral Hazard, and Agricultural Chemical Use." American Journal of Agricultural Economics 78:428-438.

Wickart, M., and R. Madlener. 2007. "Optimal technology choice and investment timing: A stochastic model of industrial cogeneration vs. heat-only production." Energy Economics 29:934952.

Wu, J. 1999. "Crop Insurance, Acreage Decisions, and Nonpoint-Source Pollution." American Journal of Agricultural Economics 81:305-320. 


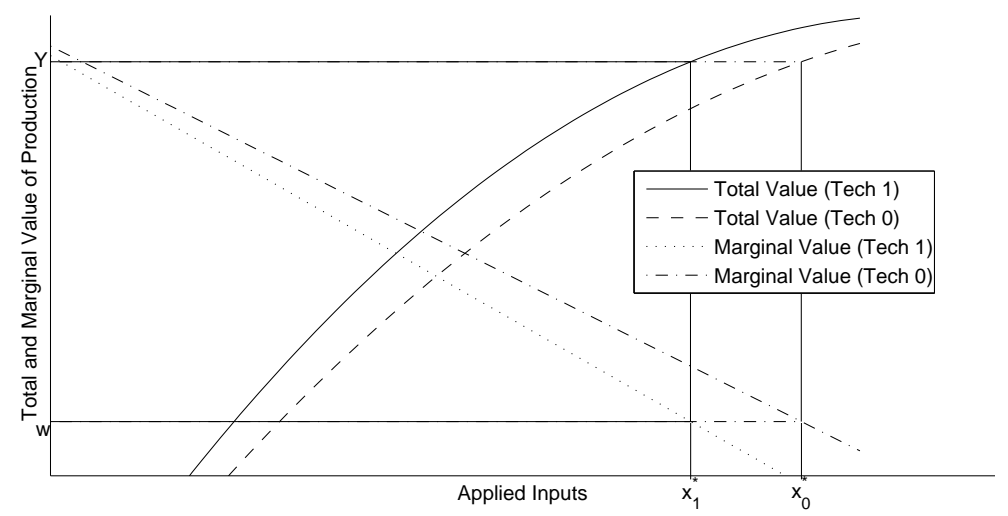

Figure 1: Production from Applied Inputs

Table 1: Distribution of Fields by Crop and Irrigation Type Perennial Annual Total

\begin{tabular}{lrrr}
\hline Conservation & 2046 & 1741 & 3787 \\
Gravity & 876 & 101 & 977 \\
Total & 2922 & 1842 & \\
\hline
\end{tabular}

Table 2: Summary Statistics of Production and Environmental Data

\begin{tabular}{lll}
\hline Variable & Mean & $\begin{array}{l}\text { Standard } \\
\text { Error }\end{array}$ \\
\hline Service area (=1 if surface water, 0 else) & 0.444 & 0.497 \\
Size of Field (acres) & 46.8 & 45.4 \\
Firm size (acres) & 309.4 & 530.9 \\
Slope (percent) & 1.51 & 1.17 \\
Soil Permeability (inches/hour) & 3.32 & 3.00 \\
Frost-free days (average days per year) & 271.4 & 7.74 \\
Elevation (feet above sea level) & 529.5 & 118.3 \\
Average precipitation (inches per year) & 7.09 & 1.08 \\
Average temperature (degrees Fahrenheit) & 63.3 & 0.92 \\
Marginal water price (dollars per acre-foot) & 58.71 & 12.10 \\
\hline Number of Observations & 4764 & \\
\hline
\end{tabular}




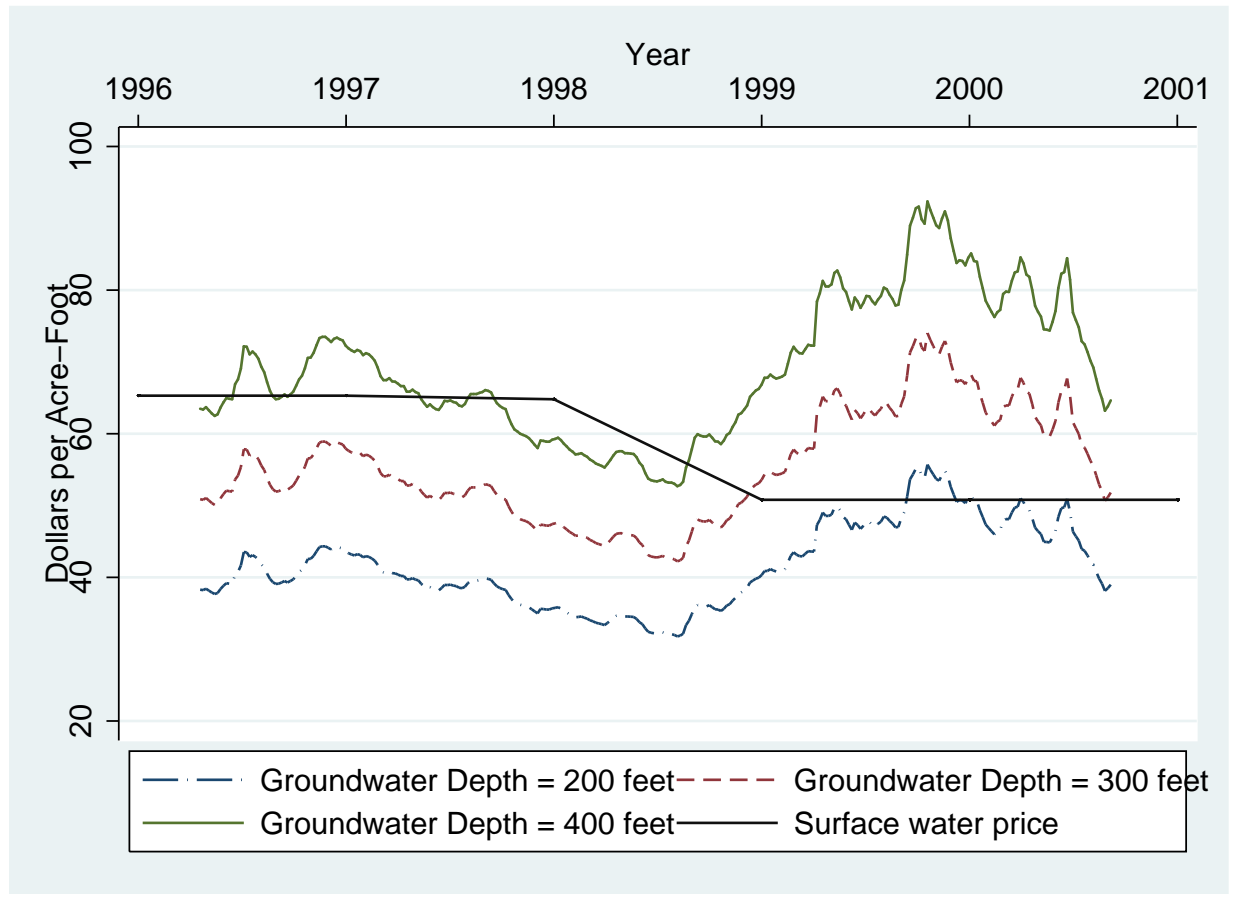

Figure 2: Marginal Cost per Acre-Foot for Groundwater and Surface Water 
Table 3: Differences in Variable Means by Water Service Area

\begin{tabular}{|c|c|c|c|c|}
\hline \multirow[b]{2}{*}{ Variable } & \multicolumn{4}{|c|}{ Full Sample } \\
\hline & $\begin{array}{l}\text { Groundwater } \\
\text { Service Area }\end{array}$ & $\begin{array}{l}\text { Surface Water } \\
\text { Service Area }\end{array}$ & $\begin{array}{r}\text { Test of Mean } \\
\text { Differences }\end{array}$ & $\begin{array}{r}\text { Percent } \\
\text { Difference }\end{array}$ \\
\hline Field size (acres) & 44.9 & 48.3 & -1.22 & 7.0 \\
\hline Firm size (acres) & 276.9 & 319.1 & -0.63 & 13.2 \\
\hline Slope & 1.20 & 1.75 & $-9.10^{* * *}$ & 31.4 \\
\hline Soil permeability & 3.80 & 2.42 & $8.43^{* * *}$ & 36.3 \\
\hline Frost-free days & 272.8 & 270.6 & $5.28 * * *$ & 0.8 \\
\hline Elevation & 488.5 & 582.1 & $-14.3^{* * *}$ & 16.8 \\
\hline Precipitation & 6.97 & 7.10 & $-2.15^{* *}$ & 1.8 \\
\hline Temperature & 63.5 & 63.1 & $7.94^{* * *}$ & 0.6 \\
\hline Township $11^{\psi}$ & 0.135 & 0.212 & $-3.49 * * *$ & 36.3 \\
\hline Township $12^{\psi}$ & 0.029 & 0.104 & $-5.27 * * *$ & 72.1 \\
\hline Township $29^{\psi}$ & 0.011 & 0.083 & $-6.09 * * *$ & 86.7 \\
\hline Township $30^{\psi}$ & 0.318 & 0.307 & 0.43 & 3.5 \\
\hline Township $31^{\psi}$ & 0.331 & 0.150 & $7.14^{* * *}$ & 54.7 \\
\hline Township $32^{\psi}$ & 0.175 & 0.144 & 1.46 & 17.7 \\
\hline Number of Observations & 2648 & 2116 & & \\
\hline
\end{tabular}

Z-statistics are listed for discrete variables while T-statistics are listed for continuous variables. A $\psi$ superscript denotes that the variable is a dummy variable. Statistical significance of differences at the $0.01,0.05$, and 0.1 levels denoted by ***,**, and * respectively. 

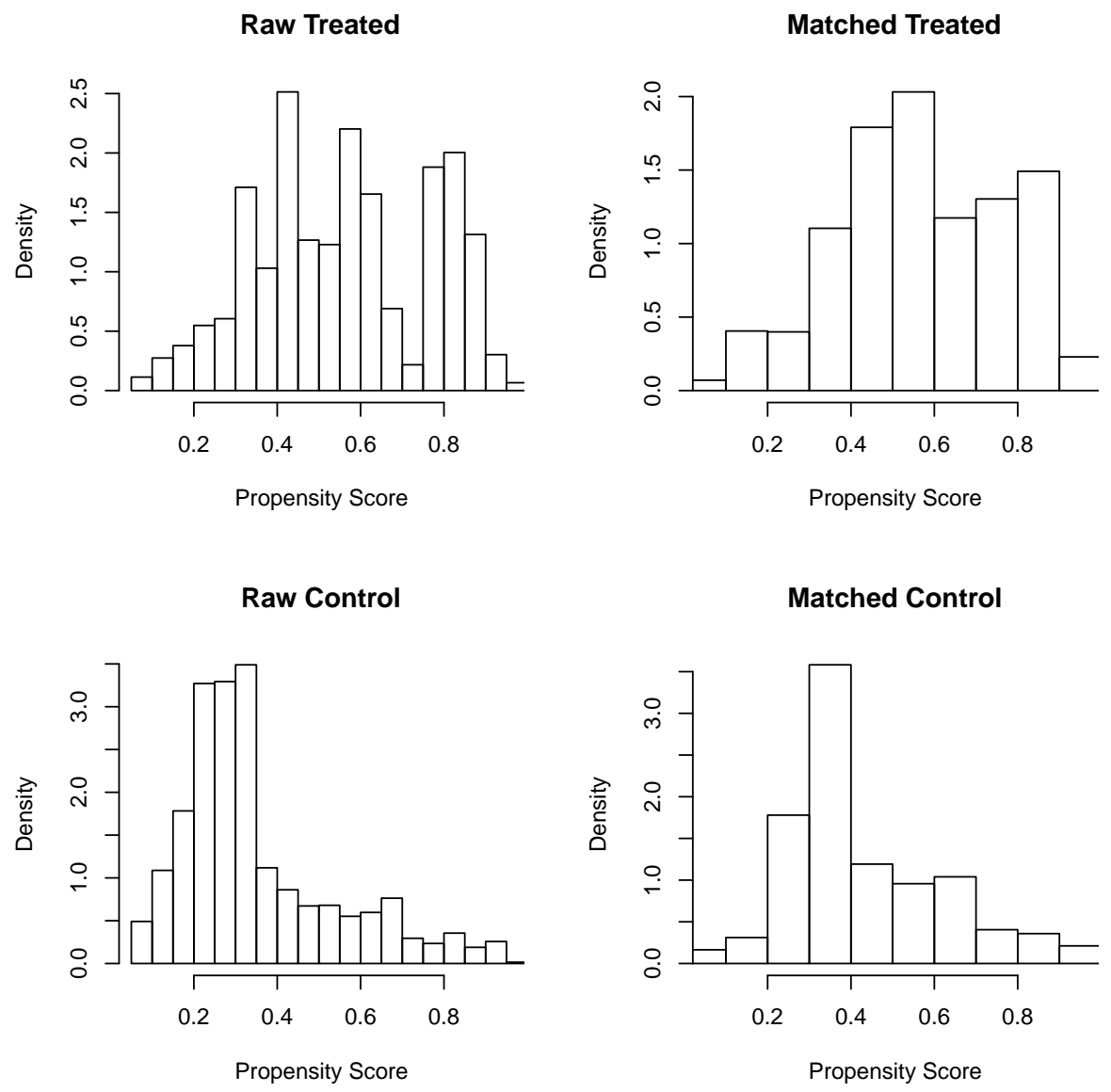

Figure 3: Histogram of Propensity Scores Pre- and Post- Matching 
Distribution of Propensity Scores

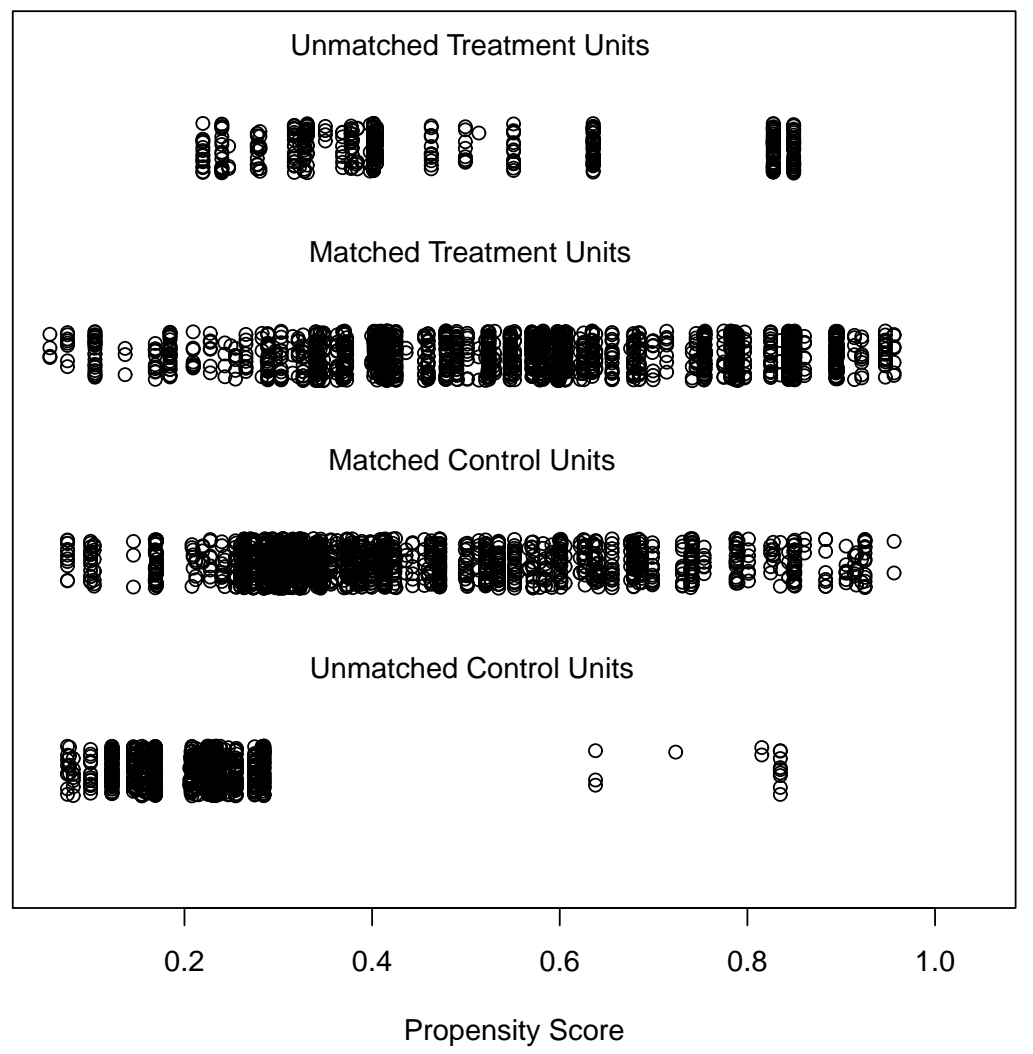

Figure 4: Jitter Plot of Propensity Scores Pre- and Post- Matching 
Table 4: Comparison of Actual and Predicted Outcomes $(\mathrm{N}=3406)$

Perennial Conservation Percent Correctly Predicted Total Observations

$\begin{array}{llcc}\text { Yes } & \text { Yes } & 77.4 & 1,110 \\ \text { Yes } & \text { No } & 65.3 & 943 \\ \text { No } & \text { Yes } & 80.7 & 57 \\ \text { No } & \text { No } & 100 & 3\end{array}$

We count a prediction as correct if the probability associated with the actual outcome is over 0.5. The 100 percent correct outcome for observations in annual crops with gravity irrigation is due to a small number of total observations $(\mathrm{N}=3)$. 


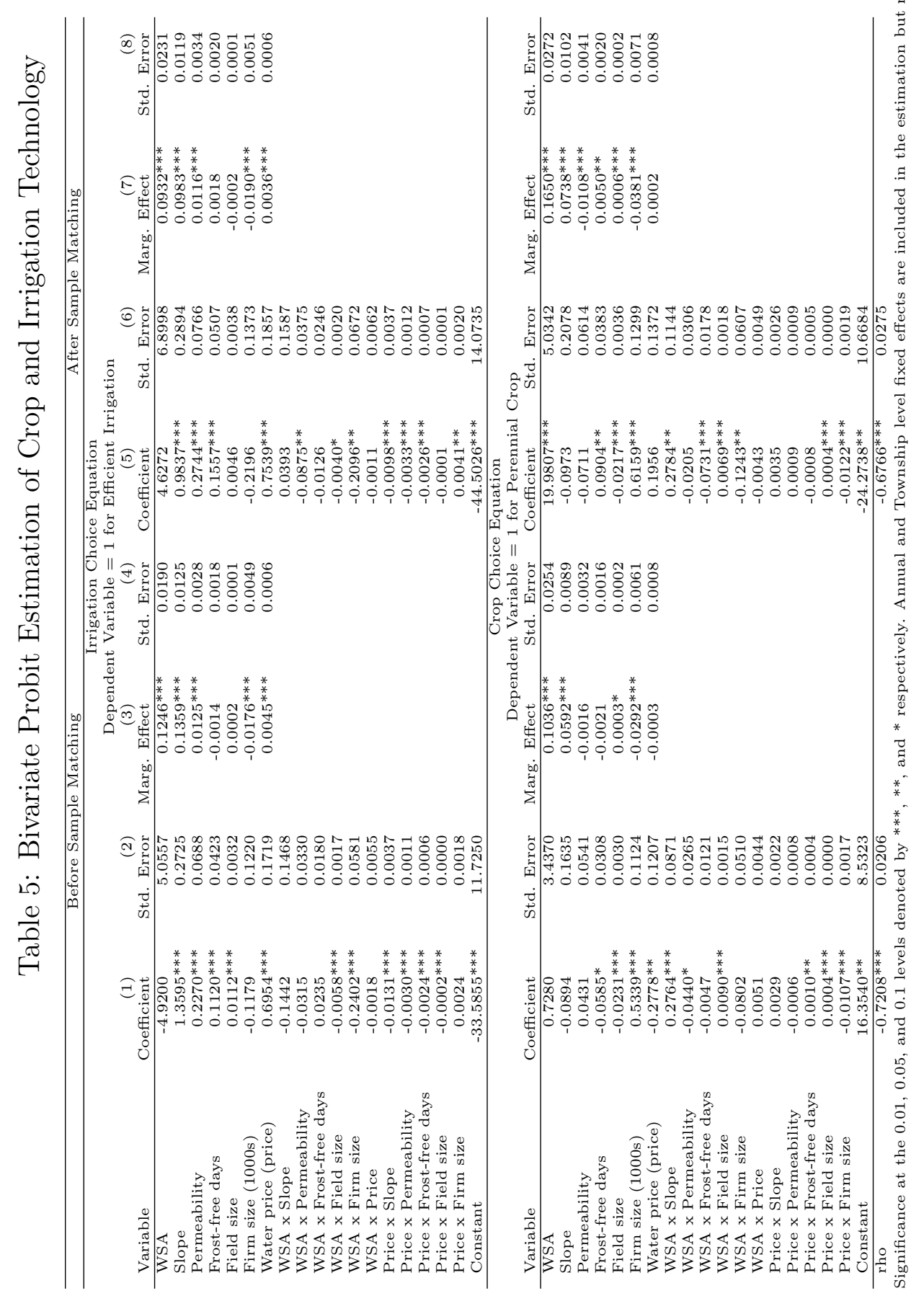

